\title{
Mortality inequality in two native population groups
}

\author{
Jan Saarela and Fjalar Finnäs
}

Åbo Akademi University

\begin{abstract}
A sample of people aged 40-67 years, taken from a longitudinal register compiled by Statistics Finland, is used to analyse mortality differences between Swedish speakers and Finnish speakers in Finland. Finnish speakers are known to have higher death rates than Swedish speakers. The purpose is to explore whether labour-market experience and partnership status, treated as proxies for measures of variation in healthrelated characteristics, are related to the mortality differential. Persons who are single, disability pensioners, and those having experienced unemployment are found to have substantially higher death rates than those with a partner and employed persons. Swedish speakers have a more favourable distribution on both variables, which thus notably helps to reduce the Finnish-Swedish mortality gradient. A conclusion from this study is that future analyses on the topic should focus on mechanisms that bring a greater proportion of Finnish speakers into the groups with poor health or supposed unhealthy behaviour.
\end{abstract}

Keywords: mortality; risk groups; population groups; unemployment; partnership status

[Submitted August 2004; Final version accepted June 2005]

\section{Introduction}

In spite of a considerable decline in mortality rates in Finland, the life expectancy of men is still 0.6 of a year shorter and of women 0.1 of a year shorter than that of the mean level in the European Union. The shortfall is even greater when life expectancy in Finland is compared with that of the neighbouring countries Sweden and Norway. A newborn boy is expected to live 2.8 years less in Finland than in Sweden and a newborn girl 0.6 of a year less (Statistics Finland 2003).

However, there is considerable variation in death rates also within Finland. Men in the 6 per cent of the population who are Swedish speaking live 2.5 years longer than those in the Finnish-speaking majority, and women 1 year longer (Finnäs 2002). To some extent this mortality gradient can be attributed to geographical concentration, since practically all Swedish speakers live in the western parts of Finland where life expectancy is 2 years longer than in eastern parts (Statistics Finland 1993). However, a considerable mortality differential remains between the two native population groups after having accounted for geographical, socio-economic, and demographic confounders (Koskinen and Martelin 2003; Martelin 1994).
Up to the present, most discussion about this mortality gradient has focused on the question of why the death rates of Swedish speakers are relatively low, rather than on the issue of why those of Finnish speakers are relatively high. Potential explanations have thus, somewhat paradoxically, been sought in the positive activities of Swedish speakers rather than in behavioural and environmental factors related to Finnish speakers. It has, for instance, been argued that the health of Swedish speakers benefits from their more extensive social networks (Hyyppä and Mäki 2001a,b). Some attempts have also been made to analyse the phenomenon by studying cause-specific mortality (Koskinen and Martelin 2003).

Previous Finnish studies have found that deaths at working ages are concentrated in certain demographic and socio-economic groups that have unhealthy behaviour, risky lifestyles, and poor health (Pekkanen et al. 1995; Kauhanen et al. 1997; Mäkelä et al. 1997). We believe that more effort needs to be focused on identifying such subgroups with elevated mortality risks if we are to achieve a better understanding of the Finnish-Swedish mortality differential. Alcohol-related causes of death amount to nearly one-third of all deaths of males of working age (Mäkelä 1998), and Finnish speakers' risk of 
alcohol-related mortality is twice that of Swedish speakers (Blomgren et al. 2004). Accidental and violent deaths have also been found to be relatively more common in the Finnish-speaking than in the Swedish-speaking population (Koskinen and Martelin 2003). As there appear to be some genetic differentials (Virtaranta-Knowles et al. 1991), it is plausible that there could be variation also in the prevalence of hereditary diseases.

An obvious reason for the paucity of studies in this area is the belief that the information needed is not included in ordinary population registers. However, the present study is based on the view that the data in the registers on partnership status and labour-market experience can be used to contribute to an understanding of the mortality differentials because unemployment, retirement on grounds of disability, and cohabitation status are all known to be highly correlated with mortality (Moser et al. 1984; Iversen et al. 1987; $\mathrm{Hu}$ and Goldman 1990; Martikainen 1990; Koskinen and Martelin 1994; Martikainen and Valkonen 1999; Lund et al. 2002).

Although the correlations are strong, causality is not indisputable. In certain economic circumstances unemployment is highly selective and related to the accumulation of disadvantage and poor position in the labour market (Martikainen and Valkonen 1996). Thus while a high proportion of the unemployed are jobless owing to poor health, the economic and psychosocial circumstances associated with unemployment may also cause movements towards an unhealthier lifestyle (Bartley 1994). Similarly, cohabitation, marriage, and parenthood could be selective if it is the healthier persons who marry, cohabit, or become parents, but those who do so benefit from a protective effect on their health as a result of a variety of behavioural and environmental factors (Hu and Goldman 1990).

Disentangling causal relationships in an explicit manner is beyond the scope of this study. Instead we set out to investigate whether partnership status and labour-market experience could help to explain the Finnish-Swedish mortality differential in Finland. We expected them to do because differences between groups in these variables are associated with differences in mortality-related characteristics, such as poor health, that are related to mortality, and Swedish speakers have lower rates of unemployment, retirement on grounds of disability, and marital dissolution than Finnish speakers (Finnäs 1997; Saarela and Finnäs 2002, 2003).

\section{Data and methods}

We use a sample (permission number TK-53-602-02) from a datafile called Työssäkäyntitilasto that was compiled from a population register by Statistics Finland (2004). The file contains individual-level data on labour-market variables linked to basic socio-economic and demographic factors. It records annual data on individuals, and the file is updated regularly at Statistics Finland. Finnish population registers include data on the unique mother tongue of every citizen, thus allowing the two population groups to be readily distinguished. Because the register is built up from cross-sectional data, it does not include information to show whether a person who is present one year but missing the next has emigrated or died. However, this information was included at our request in the sample used. No information about cause of death is available.

Using the data in the file, we are able to calculate annual age-specific death risks, which constitute our dependent variable, while taking into account their interrelationships with a number of background variables. The statistical analyses are based on transition rate (hazard) models, implying that the death risk for each sex is modelled as a function of the continuous variables age and calendar year, and the categorical explanatory variables population group, educational level, partnership status, labourmarket experience, and birth region. All variables except population group, sex, and birth region may vary over time on an individual basis. Parameters of the model are presented in exponentiated form as mortality ratios, which have a straightforward interpretation. People with a ratio of, say, 1.50 have a 50 per cent higher mortality rate than those in the reference group. All analyses are performed with the program aML 2.05 .

The sample used covers the years 1989-99, and has been designed to facilitate comparisons between the two population groups of interest. It is a stratified random sample, comprising 20 per cent of all Swedish speakers and 5 per cent of all Finnish speakers born before 1984, geographically restricted to persons who lived in bilingual or monolingual Swedish municipalities in any of the years mentioned. About 95 per cent of all Swedish speakers in Finland live in these municipalities, the locations of which are shown on the map in Figure 1.

We analyse death rates in the age range 40-67 years. The total (unweighted) number of individuals studied is 27,686 for Swedish speakers and 29,461 for Finnish speakers. They represent in total 441,234 


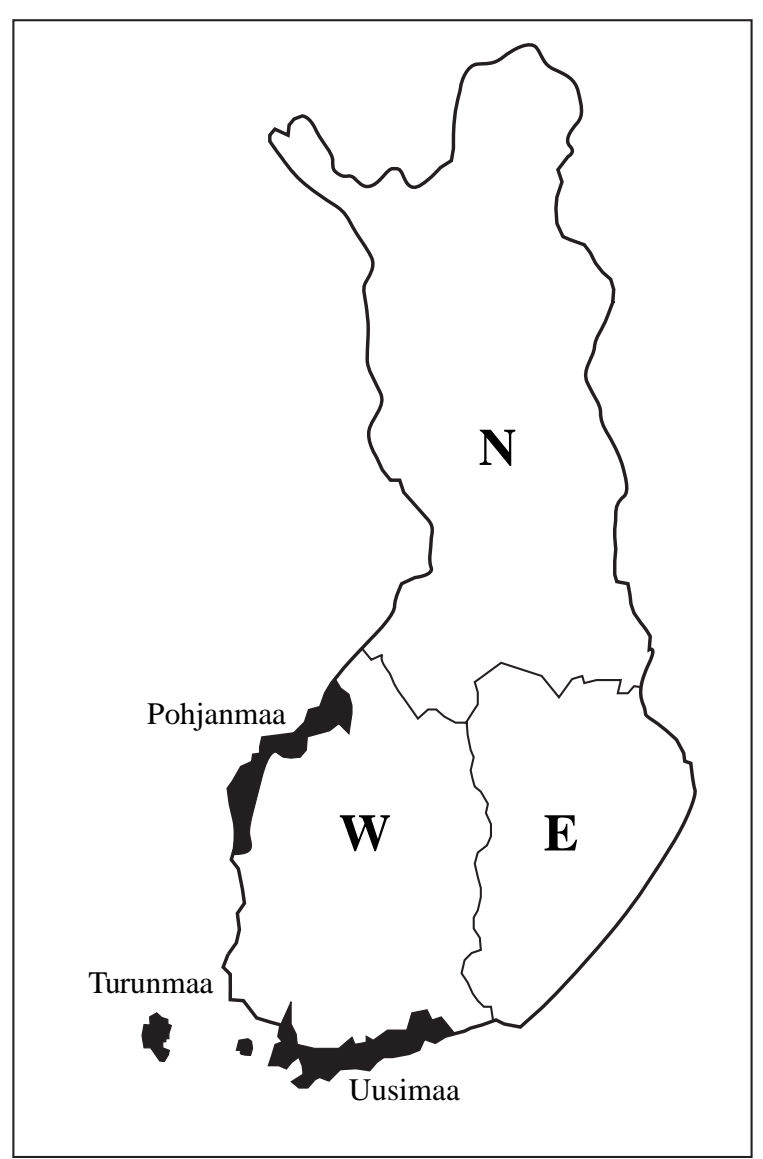

Figure 1 Map of Finland showing classification of region of birth and location of Swedish speakers

Note: The shaded areas refer to municipalities in which 95 per cent of all Finland's Swedish speakers live, that is, the areas that are under study in the paper. Birth region is classified into the categories: Western Finland (W), Eastern Finland (E), and Northern Finland (N)

person-years. The number of deaths is 1,741 for men and 857 for women.

Initially we tried to include an indicator of region of residence (within the area studied). This turned out to be less important than region of birth, which had a significant impact on risk of death and contributed substantially to the Finnish-Swedish mortality differential. Consequently, region of birth is included in the results reported here, and categorized according to the division of the country indicated in Figure 1. The importance of this variable has also been demonstrated in previous studies, according to which the reason why region of birth is more highly correlated with mortality than region of residence is the extensive internal migration of Finnish speakers in Finland (Valkonen 1987).

For partnership status we combine information about marital status, type of family, and position in the family. The population register in Finland contains information about consensual unions, and no distinction is made between these and formal marriages. We use three categories: persons with a partner, persons living alone, and all others. The 'all others' category consists mainly of persons living with their parents and single parents living with children. A majority of those living alone were previously married.

Labour-market experience comprises, where applicable, information for the five previous (most recent) years. Initially we experimented with time windows of various lengths and found that the results were rather stable. A reason for using the 5 -year period was that it enabled us to include people somewhat above working age, and therefore a higher number of deaths. People younger than 40 years are excluded because the meaning of the partnership variable differs between younger and older age groups, and because there are quite a few deaths at these ages. A person is considered to be a pensioner for reasons of disability if he or she received a disability pension (which need not be a permanent pension) in any of the years. If the person was unemployed in any month during the period, and did not receive a disability pension, he or she is classified as unemployed. A person is classified as employed if he or she was employed in any month, and neither received a disability pension nor was unemployed. In all other cases, a person is assigned to the 'other' category, which consequently consists of people who have been continuously outside the labour market for some reason other than having been a disability pensioner.

Educational level is classified into the categories basic, vocational, and undergraduate or higher.

Originally, we also tried to include various income variables in the estimations, but found no indications whatsoever that income differences affected the Finnish-Swedish mortality differential. Those results are therefore not presented here.

\section{Results}

Table 1 shows the distribution of control variables as percentages of total time at risk and the number of deaths by sex and population group. As expected, there are, particularly for men, considerable differences between the two population groups in the proportion of people in categories presumed to have elevated mortality. Whereas 20 per cent of Finnishspeaking men belong to the group that had experience of unemployment, for Swedish speakers the corresponding figure is 14 per cent. The percentage of persons living alone in the Finnish-speaking male population is 21 per cent but is only 16 per cent for 
Table 1 Percentage distribution of variables and number of deaths by sex and population group in a sample used for a study of the Finnish-Swedish mortality gradient 1989-99

\begin{tabular}{|c|c|c|c|c|c|c|c|c|}
\hline & \multicolumn{4}{|l|}{ Men } & \multicolumn{4}{|c|}{ Women } \\
\hline & \multicolumn{2}{|c|}{ Per cent time at risk } & \multicolumn{2}{|c|}{ Number of deaths } & \multicolumn{2}{|c|}{ Per cent time at risk } & \multicolumn{2}{|c|}{ Number of deaths } \\
\hline & Swed. & Finn. & Swed. & Finn. & Swed. & Finn. & Swed. & Finn. \\
\hline \multicolumn{9}{|l|}{ Age in years } \\
\hline $40-49$ & 41.8 & 48.1 & 129 & 197 & 40.3 & 46.4 & 63 & 110 \\
\hline $50-59$ & 34.7 & 34.0 & 253 & 336 & 34.2 & 33.7 & 117 & 151 \\
\hline $60-67$ & 23.5 & 17.9 & 420 & 406 & 25.5 & 19.8 & 218 & 198 \\
\hline \multicolumn{9}{|l|}{ Calendar time in years } \\
\hline 1989-91 & 27.1 & 25.2 & 260 & 255 & 27.5 & 25.5 & 126 & 155 \\
\hline $1992-95$ & 36.4 & 36.1 & 295 & 348 & 36.3 & 36.1 & 149 & 150 \\
\hline 1996-99 & 36.5 & 38.6 & 247 & 336 & 36.2 & 38.4 & 123 & 154 \\
\hline \multicolumn{9}{|l|}{ Educational level } \\
\hline Basic & 47.0 & 42.1 & 496 & 579 & 50.4 & 45.0 & 260 & 314 \\
\hline Vocational & 35.9 & 39.0 & 222 & 273 & 38.1 & 40.9 & 108 & 119 \\
\hline Undergraduate or higher & 17.1 & 18.9 & 84 & 87 & 11.4 & 14.1 & 30 & 26 \\
\hline \multicolumn{9}{|l|}{ Birth region } \\
\hline Western Finland & 98.9 & 68.0 & 792 & 571 & 98.5 & 64.7 & 394 & 274 \\
\hline Eastern Finland & 0.9 & 24.3 & 5 & 299 & 1.1 & 27.0 & 3 & 159 \\
\hline Northern Finland & 0.2 & 7.7 & 5 & 69 & 0.4 & 8.3 & 1 & 26 \\
\hline \multicolumn{9}{|l|}{ Partnership status } \\
\hline With partner & 78.3 & 72.9 & 486 & 462 & 73.1 & 63.2 & 235 & 206 \\
\hline Single & 15.7 & 21.4 & 255 & 398 & 17.3 & 25.2 & 122 & 203 \\
\hline Other & 6.0 & 5.7 & 61 & 79 & 9.6 & 11.6 & 41 & 50 \\
\hline \multicolumn{9}{|l|}{ Labour-market experience } \\
\hline Employed & 68.0 & 62.8 & 264 & 222 & 66.0 & 66.5 & 124 & 126 \\
\hline Unemployed & 14.2 & 19.9 & 110 & 198 & 13.2 & 14.9 & 38 & 51 \\
\hline Disability pensioner & 11.4 & 12.8 & 327 & 411 & 10.0 & 11.3 & 174 & 242 \\
\hline Other & 6.4 & 4.6 & 101 & 108 & 10.8 & 7.3 & 62 & 40 \\
\hline Total & 100.0 & 100.0 & 802 & 939 & 100.0 & 100.0 & 398 & 459 \\
\hline
\end{tabular}

${ }^{1}$ The total number of Swedish-speaking men in the data is 14,067, Finnish-speaking men 14,151, Swedish-speaking women 13,619, and Finnish-speaking women 15,310.

Source: Työssäkäyntitilasto, 1989-99.

Swedish speakers. For women, the difference in partnership status between population groups is similar to that of men, whereas there is smaller variation in labour-market experience. If partnership status and labour-market experience are combined, almost 60 per cent of the Swedish-speaking men but only half of the Finnish speakers belong to the socially most successful category, that is, those who both cohabit and are employed (details not shown).

We first calculated models that adjusted for the basic variables educational level, calendar year, and birth region (not shown). This reduced the difference in mortality risk between the two male population groups from 33 to 27 per cent. Next, we sequentially included partnership status and labourmarket experience, which resulted in the models shown in Table 2. The impact of each of these variables is considerable. A single man's risk of death is twice that of a man with a partner. Similarly, having experience of unemployment is associated with a risk of death twice as high as that for having been economically active. Disability pension is evidently an indicator of very poor health: persons who have retired owing to disability have three times the mortality risk of the economically active. Since Swedish speakers have a more favourable distribution on partnership status and labour-market experience, the inclusion of these factors notably reduces the difference in mortality between population groups. The contribution of partnership status alone implies a reduction of the difference in risk to 21 per cent, and this falls to 16 per cent when labourmarket experience is also taken into account.

For women the effect is somewhat smaller than that for men, while disability pension is related to an even higher mortality risk than that of men. The 
Table 2 Estimated impact of background variables on mortality hazard ratios according to main-effects models, Finland 1989-99 ${ }^{1}$

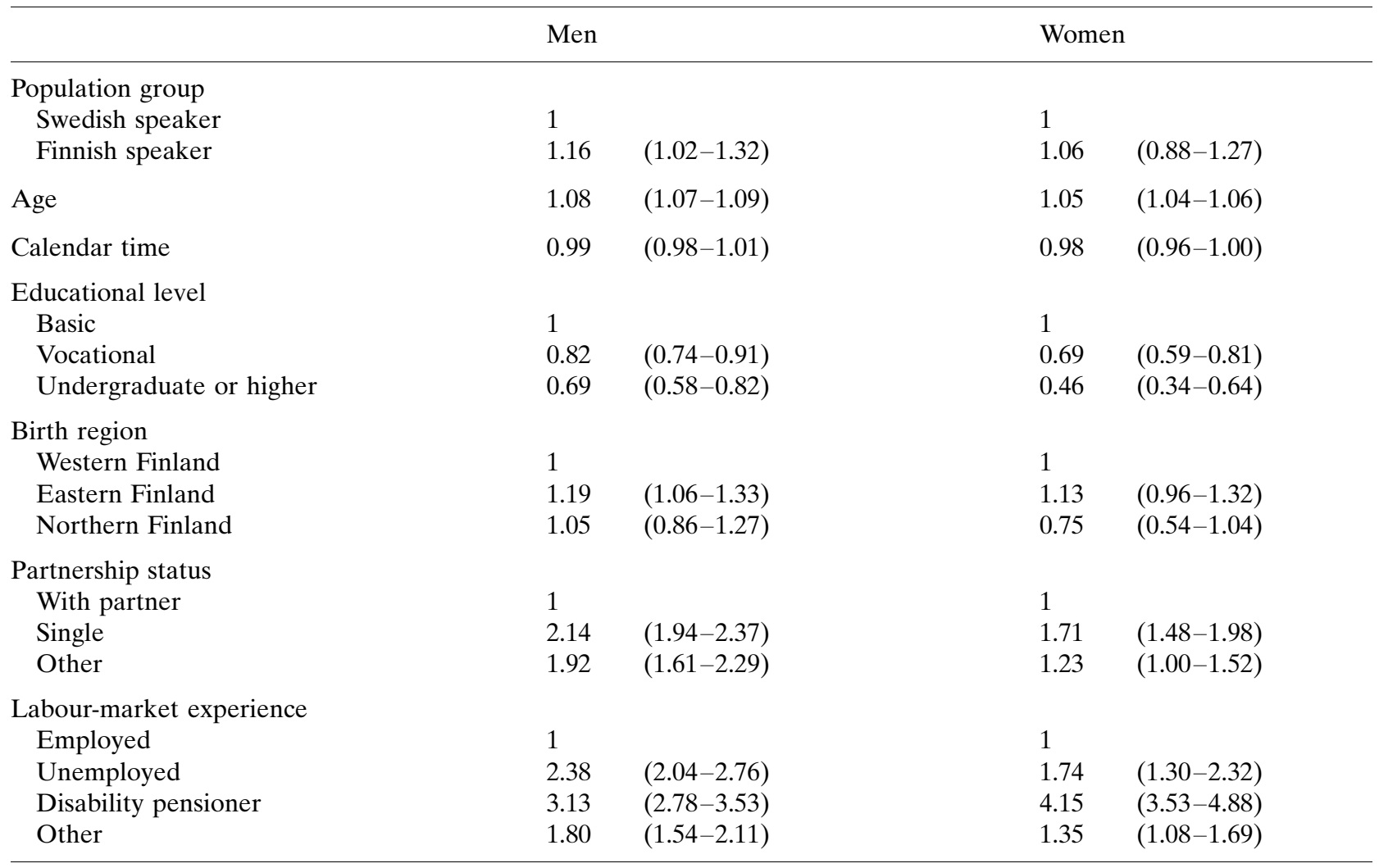

${ }^{1}$ Ninety-five per cent confidence intervals are in parentheses.

Source: As for Table 1.

overall age-adjusted difference in risk of death between the two population groups falls from 18 to 16 per cent when educational level, calendar year, and region of birth are taken into account. When partnership status is included the difference is 9 per cent and is no longer statistically significant, and it falls to only 6 per cent when labour-market experience is also taken into account.

The main-effects models imply that the difference in mortality between population groups is the same in all subgroups. Given that certain causes of death have been found concentrated in particular socioeconomic and demographic segments of the population, and that our variables should be seen as indicators of unmeasured characteristics related to the risk of mortality, a natural extension of the maineffects model is a model that incorporates parameters that account for the three-way interaction between population group, partnership status, and labour-market experience.

For men these parameters show a very interesting pattern (Table 3 ). In the subgroup that was successful both in family formation and in the labour market, that is, cohabiting persons in employment, there is practically no difference between people of each population group. Indeed the mortality level of the Finnish speakers is even somewhat lower than that of Swedish speakers. In all other combinations, however, Finnish speakers have higher mortality rates than Swedish speakers. In spite of the fact that the difference between population groups is not statistically significant in any of these categories, the pattern is consistent and very clear.

For women too, the mortality rates of Swedish speakers and Finnish speakers coincide among employed persons with a partner. In the other categories there is a tendency for results to be similar to those for men, but the pattern is not equally consistent.

\section{Discussion}

This study has focused on the question of how mortality in working ages is related to partnership status and labour-market experience. These variables have been interpreted here as crude proxies for unobserved characteristics related to mortality risk, and are used to identify subgroups that have elevated mortality owing to poor health or 
Table 3 Estimated impact of population group, partnership status, and labour-market experience on mortality hazard ratios according to a model with interaction effects, Finland 1989-99 ${ }^{1}$

\begin{tabular}{|c|c|c|c|c|c|c|}
\hline & \multicolumn{2}{|l|}{ With partner } & \multicolumn{2}{|l|}{ Single } & \multicolumn{2}{|l|}{ Other } \\
\hline & Swedish & Finnish & Swedish & Finnish & Swedish & Finnish \\
\hline \multicolumn{7}{|l|}{ Men } \\
\hline Employed & 1 & $\begin{array}{l}0.96 \\
(0.78-1.18)\end{array}$ & $\begin{array}{l}1.43 \\
(0.96-2.13)\end{array}$ & $\begin{array}{l}2.39 \\
(1.92-2.98)\end{array}$ & $\begin{array}{l}1.90 \\
(1.11-3.26)\end{array}$ & $\begin{array}{l}2.08 \\
(1.44-3.00)\end{array}$ \\
\hline Unemployed & $\begin{array}{l}1.96 \\
(1.02-3.78)\end{array}$ & $\begin{array}{l}2.35 \\
(1.70-3.25)\end{array}$ & $\begin{array}{l}5.15 \\
(2.95-8.98)\end{array}$ & $\begin{array}{l}5.39 \\
(4.18-6.95)\end{array}$ & $\begin{array}{l}3.15 \\
(0.86-11.54)\end{array}$ & $\begin{array}{l}4.35 \\
(2.84-6.68)\end{array}$ \\
\hline $\begin{array}{l}\text { Disability } \\
\text { pensioner }\end{array}$ & $\begin{array}{l}3.02 \\
(2.12-4.32)\end{array}$ & $\begin{array}{l}3.62 \\
(2.86-4.57)\end{array}$ & $\begin{array}{l}5.26 \\
(3.53-7.86)\end{array}$ & $\begin{array}{l}6.33 \\
(5.00-8.02)\end{array}$ & $\begin{array}{l}5.71 \\
(3.23-10.07)\end{array}$ & $\begin{array}{l}5.74 \\
(4.02-8.20)\end{array}$ \\
\hline Other & $\begin{array}{l}1.26 \\
(0.81-1.97)\end{array}$ & $\begin{array}{l}1.84 \\
(1.38-2.43)\end{array}$ & $\begin{array}{l}3.66 \\
(2.26-5.94)\end{array}$ & $\begin{array}{l}4.20 \\
(3.18-5.56)\end{array}$ & $\begin{array}{l}0.84 \\
(0.09-7.55)\end{array}$ & $\begin{array}{l}4.57 \\
(2.70-7.73)\end{array}$ \\
\hline \multicolumn{7}{|l|}{ Women } \\
\hline Employed & 1 & $\begin{array}{l}1.02 \\
(0.74-1.41)\end{array}$ & $\begin{array}{l}1.51 \\
(0.84-2.73)\end{array}$ & $\begin{array}{l}2.05 \\
(1.46-2.87)\end{array}$ & $\begin{array}{l}2.27 \\
(1.28-4.03)\end{array}$ & $\begin{array}{l}1.10 \\
(0.72-1.68)\end{array}$ \\
\hline Unemployed & $\begin{array}{l}1.11 \\
(0.35-3.49)\end{array}$ & $\begin{array}{l}1.58 \\
(0.90-2.76)\end{array}$ & $\begin{array}{l}7.93 \\
(3.25-19.35)\end{array}$ & $\begin{array}{l}4.07 \\
(2.43-6.80)\end{array}$ & $\begin{array}{l}0.68 \\
(0.03-16.61)\end{array}$ & $\begin{array}{l}1.51 \\
(0.58-3.95)\end{array}$ \\
\hline $\begin{array}{l}\text { Disability } \\
\text { pensioner }\end{array}$ & $\begin{array}{l}5.18 \\
(3.16-8.51)\end{array}$ & $\begin{array}{l}5.37 \\
(3.77-7.65)\end{array}$ & $\begin{array}{l}4.86 \\
(2.58-9.15)\end{array}$ & $\begin{array}{l}6.68 \\
(4.70-9.49)\end{array}$ & $\begin{array}{l}3.39 \\
(1.26-9.09)\end{array}$ & $\begin{array}{l}6.83 \\
(4.40-10.62)\end{array}$ \\
\hline Other & $\begin{array}{l}1.44 \\
(0.82-2.52)\end{array}$ & $\begin{array}{l}1.31 \\
(0.85-2.02)\end{array}$ & $\begin{array}{l}2.28 \\
(1.06-4.90)\end{array}$ & $\begin{array}{l}2.87 \\
(1.86-4.43)\end{array}$ & $\begin{array}{l}1.85 \\
(0.43-8.02)\end{array}$ & $\begin{array}{l}1.70 \\
(0.73-3.96)\end{array}$ \\
\hline
\end{tabular}

${ }^{1}$ The ratios are adjusted for age, calendar time, educational level, and birth region. Ninety-five per cent confidence intervals are in parentheses.

Source: As for Table 1.

unhealthy lifestyles. Previous research has shown that cause-specific deaths, such as those related to the use of alcohol and violence, are concentrated in specific segments of the population. However, population registers do not provide details of health and psychosocial conditions. We therefore set out to take these into account by analysing the mortality differentials between subgroups known to differ in their health-related characteristics, in the belief that this would help to show why overall mortality is higher for the Finnish-speaking than for the Swedish-speaking population group in Finland.

The contribution of partnership status and labourmarket experience to the overall mortality risk turns out to be substantial, and the difference in mortality between the two population groups falls remarkably when these variables are taken into account. The reason for this is that Swedish speakers have a more favourable distribution on these variables: they are less likely to be unemployed, to retire on grounds of disability, and to be divorced. In a basic model taking into account age, educational level, calendar year, and region of birth, the mortality risk of male Finnish speakers is 27 per cent higher than that of Swedish speakers, but it is only 16 per cent when partnership status and labour-market experience are included. For women the corresponding proportions are 16 and 6 per cent, respectively.
In addition the inclusion of a test for three-way interactions between population group, partnership status, and labour-market experience illustrates a very interesting pattern. In the socially most successful group, that is, married persons who are employed, there is no difference between Finnish speakers and Swedish speakers. Almost 60 per cent of Swedish-speaking men belong to this group but only half the Finnish speakers. On the other hand, in the disadvantaged groups with clearly elevated mortality levels, some difference in mortality between the two population groups seems to remain, at least among men. The importance of the contribution of these disadvantaged groups to overall death rates in working ages is illustrated by the fact that although only one-tenth of Finnish-speaking men are single and have experience of unemployment, they still account for almost one-third of all deaths.

The results are similar but not equally convincing for women. One obvious reason for this is that the overall mortality difference is rather small. Another may be that there are differences by sex in a number of the unobserved characteristics associated with excess mortality, as shown by previous findings (Sacker et al. 2000; Pensola 2003; Skrabski et al. 2003).

As indicators of unobserved characteristics, the variables we have used are rather crude, albeit 
among the best available from the data available in population registers. Their crudeness means that we cannot claim that our findings are definitive. For the same reason, it is difficult to interpret the remaining differences in mortality between the population groups, though we think it is plausible to argue that if social networks preserve health, their beneficial impact may be stronger in socially disadvantaged groups, thus favouring Swedish speakers since they are assumed to have more extensive social networks than Finnish speakers.

We conclude from this study that variables such as partnership status and labour-market experience can be useful for investigating inequalities in mortality. However, because findings based on them cannot be given the same weight as direct measures of healthrelated characteristics, real explanations are not likely to be found in registers. Future analyses of the Finnish-Swedish mortality gradient in Finland should therefore focus on mechanisms that bring a greater proportion of Finnish speakers into groups with poor health or unhealthy behaviour. For instance, our findings indirectly support previous arguments that variation in drinking habits could be important. Thus a natural continuation of this study would be an investigation of whether deaths in disadvantaged segments of the population are strongly related to causes of death known to be linked to unhealthy behaviour. An extensive analysis of that issue would need details of people's health, as well as of their past and current habits, in order to clarify the underlying causal mechanisms.

\section{Notes}

1 Jan Saarela and Fjalar Finnäs are at Åbo Akademi University, PO Box 311, FIN-65101 Vasa, Finland. Email: fjalar.finnas@abo.fi

\section{References}

Bartley, M. 1994. Unemployment and ill health: understanding the relationship, Journal of Epidemiology and Community Health 48: 333-337.

Blomgren, J., P. Martikainen, P. Mäkelä, and T. Valkonen. 2004. The effects of regional characteristics on alcoholrelated mortality - a register-based multilevel analysis of 1.1 million men, Social Science \& Medicine 58: 2523 2535.

Finnäs, F. 1997. Social integration, heterogeneity, and divorce: the case of the Swedish-speaking population in Finland, Acta Sociologica 40: 263-277.
Finnäs, F. 2002. How long do Swedish-speaking Finns live? A comment on the paper by Hyyppä and Mäki, Health Promotion International 17: 287-290.

$\mathrm{Hu}$, Y. and N. Goldman. 1990. Mortality differentials by marital status: an international comparison, Demography 27: 233-250.

Hyyppä, M. T. and J. Mäki. 2001a. Individual-level relationships between social capital and self-rated health in a bilingual community, Preventive Medicine 32: $148-155$.

Hyyppä, M. T. and J. Mäki. 2001b. Why do Swedishspeaking Finns have longer active life? An area for social capital research, Health Promotion International 16: 55-64.

Iversen, L., O. Andersen, P. K. Andersen, K. Christoffersen, and N. Keiding. 1987. Unemployment and mortality in Denmark, British Medical Journal 295: 879-884.

Kauhanen, J., G. A. Kaplan, D. E. Goldberg, and J. T. Salonen. 1997. Beer binging and mortality: results from the Kuopio ischaemic heart disease risk factor study, a prospective population based study, British Medical Journal 315: 846-851.

Koskinen, S. and T. Martelin. 1994. Kuolleisuus, in S. Koskinen, T. Martelin, I.-L. Notkola, V. Notkola, and K Pitkänen (eds.), Suomen Väestö. Hämeenlinna: Gaudeamus, pp. 150-225.

Koskinen, S. and T. Martelin. 2003. Why is mortality low among the Swedish-speaking minority in Finland?, Yearbook of Population Research in Finland 39: 15-32.

Lund, R., P. Due, J. Modvig, B. E. Holstein, M. T. Damsgaard, and P. K. Andersen. 2002. Cohabitation and marital status as predictors of mortality - an eight year follow-up study, Social Science \& Medicine 55: 673-679.

Martelin, T. 1994. Differential mortality at older ages, Dissertation, Publications of the Finnish Demographic Society, No. 16. Helsinki: Finnish Demographic Society.

Martikainen, P. T. 1990. Unemployment and mortality among Finnish men, 1981-85, British Medical Journal 301: 407-411.

Martikainen, P. T. and T. Valkonen. 1996. Excess mortality of unemployed men and women during a period of rapidly increasing unemployment, Lancet 348: 909912.

Martikainen, P. T. and T. Valkonen. 1999. Bias related to the exclusion of the economically inactive in studies on social class differences in mortality, International Journal of Epidemiology 28: 899-904.

Moser, K. A., A. J. Fox, and D. R. Jones. 1984. Unemployment and mortality in the OPCS longitudinal study, Lancet 324: 1324-1328.

Mäkelä, P., T. Valkonen, and T. Martelin. 1997. Contribution of deaths related to alcohol use to socioeconomic 
variation in mortality: register based follow-up study, British Medical Journal 315: 211-216.

Mäkelä, P. 1998. Alcohol-related mortality by age and sex and its impact on life expectancy. Estimates based on the Finnish death register, European Journal of Public Health 8: 43-51.

Pekkanen, J., J. Tuomilehto, A. Uutela, E. Vartiainen, and A. Nissinen. 1995. Social class, health behaviour, and mortality among men and women in Eastern Finland, British Medical Journal 311: 589-593.

Pensola, T. 2003. From past to present: effect of lifecourse on mortality, and social class differences in mortality in middle adulthood, Dissertation, Yearbook of Population Research in Finland, 39(Suppl.).

Saarela, J. and F. Finnäs. 2002. Language-group differences in very early retirement in Finland, Demographic Research 7(3). Available: www.demographic-research. org/Volumes/Vol7/3

Saarela, J. and F. Finnäs. 2003. Unemployment and native language: the Finnish case, Journal of Socio-Economics 32: $59-80$.
Sacker, A., D. Firth, R. Fitzpatrick, K. Lynch, and M. Bartley. 2000. Comparing health inequality in men and women: prospective study of mortality 1986-96, British Medical Journal 320: 1303-1307.

Skrabski, Á., M. Kopp, and I. Kawachi. 2003. Social capital in a changing society: cross sectional associations with middle aged female and male mortality rates, Journal of Epidemiology and Community Health 57: 114-119.

Statistics Finland. 1993. Life tables. Population 1993: 5. Helsinki: Statistics Finland.

Statistics Finland. 2003. Vital statistics. Population 2003: 11. Helsinki: Statistics Finland.

Statistics Finland. 2004. Työssäkäynti. Available: www.stat. fi/til/tyokay

Valkonen, T. 1987. Male mortality from ischaemic heart disease in Finland: relation to region of birth and region of residence, European Journal of Population 3: 61-83.

Virtaranta-Knowles, K., P. Sistonen, and H. R. Nevanlinna. 1991. A population genetic study in Finland: comparisons of the Finnish- and Swedish-speaking populations, Human Heredity 41: 248-264. 